استخدام تقتيات التحس النائي في دراسة ظاهرة التصحر وحركة الكثبان الرملية في منطقة بيجي شمال العراق

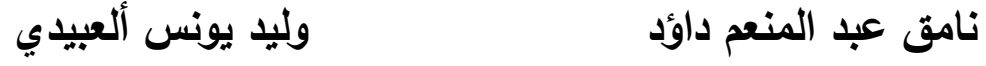

$$
\begin{aligned}
& \text { مركز التحسس النائي }
\end{aligned}
$$

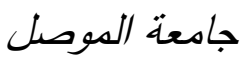

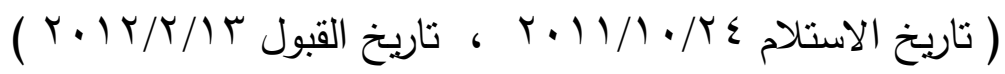

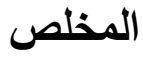

استخدمت تقنيات التحسس النائي في تحديد مناطق تواجد الكثبان الرملية في المنطقة الممتدة بين بحيرة الثرثار وباتجاه منطقة بيجي الصناعية ومعرفة مسـاحتها واتجاه حركتها بالاعتماد على المرئيات الفضائية للقمرين الاصطناعيين الامريكيين Landsat-5 TM لعام 1990 و Landsat-7 ETM+ لعام وبام 2000، وتحديد استخدامات الأرض في المنطقة مـن خـالد تحديد مواقع المنشـآت الصناعية، والطرق،

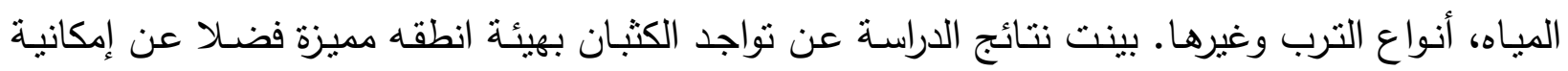
تحديد المساحة الكلبة للمناطق المغطاة بالكثبان الرملية خلال الفترة اعلاه.

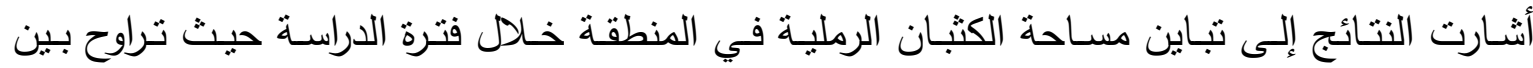

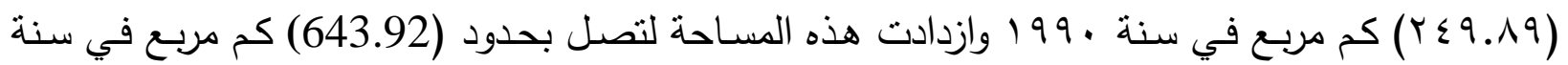

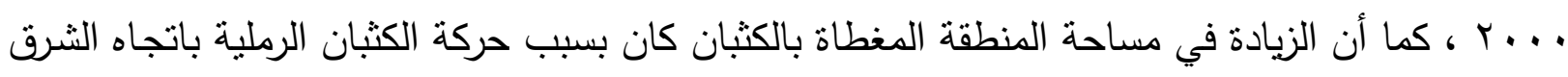
(مدينـة بيجي) والجنوب الثـرقي باتجاه مدينـة تكريت حيث أثثرت بشكل واضـح على العديد من المنشأة

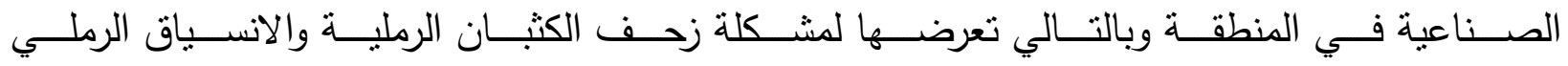

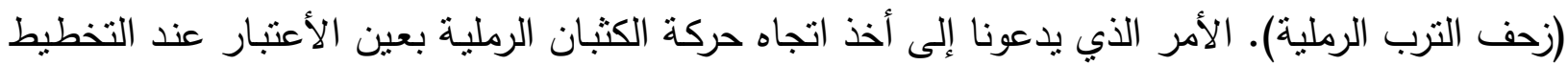

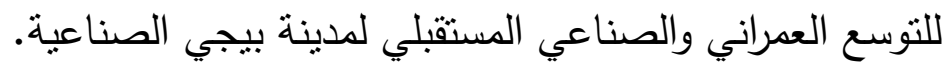
الكلمات ألمفتاحيه :التصحر ؛ الكثبان الرملية ؛ التحس النسائه النائي.

\title{
Using Remote Sensing Techniques on the Study of Desertification and the Sand Dunes Movements in Biji Area Northern Iraq
}

\author{
Namik A. Daood Waleed Y. Alubide \\ Remote Sensing Center \\ University of Mosul
}




\begin{abstract}
Remote sensing techniques had been used to identify the total areas of the land covered with sand dunes for the region to the east of Lake Al-Thar Thar and towards Biji industrial town, and detecting the direction of its movement based on data obtained from the satellite images Landsat-5 (TM) 1990, and Landsat-7 $(\mathrm{ETM}+) 2000$, also specify the land use of the region through the identification of sites of industrial plants, roads, water, rock, soils, and others. The results showed that the sand dunes presence as a characteristics bands as well as the possibility of determining the total area that covered by sand dunes during the specified interval time.

The results showed the great variety of the areas for the region covered with sand dunes and it ranging between (249.89) $\mathrm{km}^{2}$ in the year 1990 and about (643.92) $\mathrm{km} 2$ in 2000.The increases of the area covered by the sand dunes was due to the movement of sand dunes to the east of (Biji) and south-east towards Tikrit city, also many of the industrial establishment in the region was affected and exposed to the problem of sand drifting. This make the determination of the direction and the speed of movement of sand dunes taking into consideration when we planning for expansion of urban and industrial future of the industrial city of Biji.
\end{abstract}

\title{
المقدمة
}

عملية التصحر وحركة الكثبان الرملية من المشاكل البيئية التي تواجه معظم المناطق الواقعة ضمن

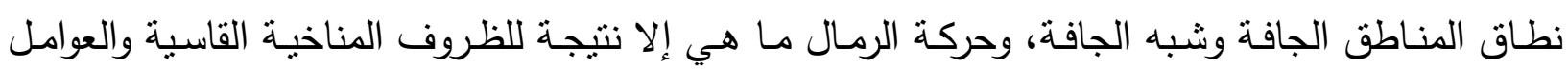

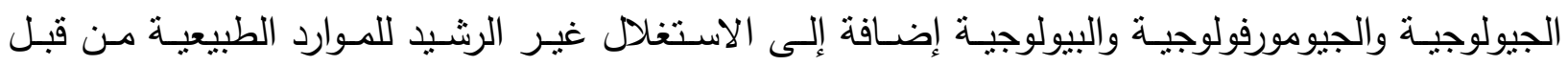

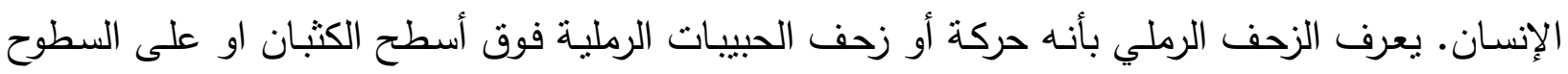

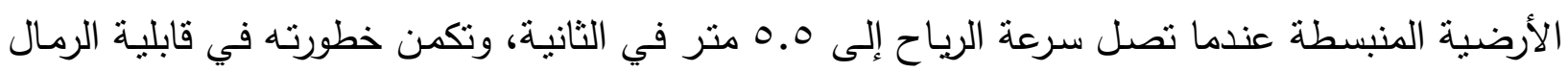

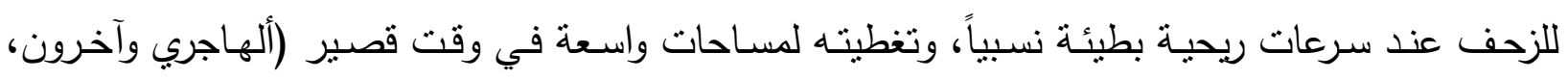

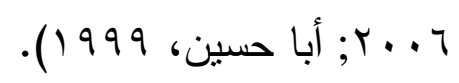

تعمل الرياح على تفتيت سطح التربة الخارجي ونقل حبيباتها مكونة ما يعرف بالتعرية الريحية والتي

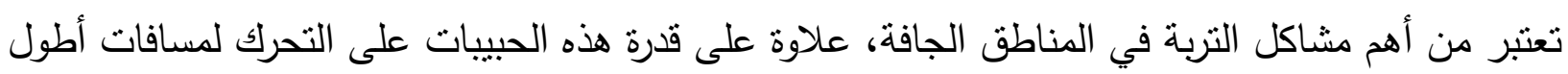

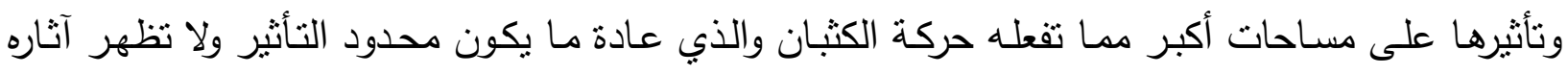

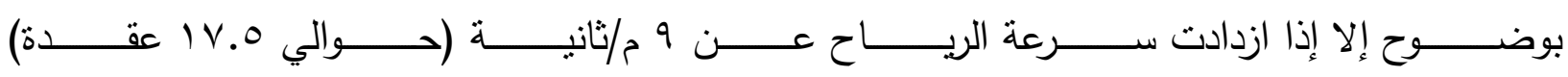

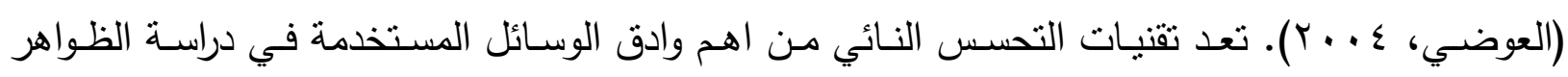

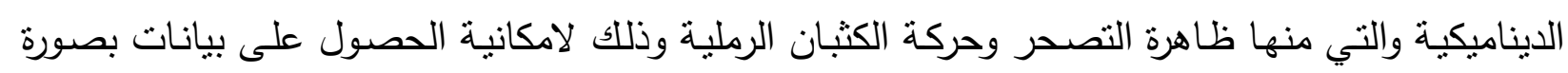

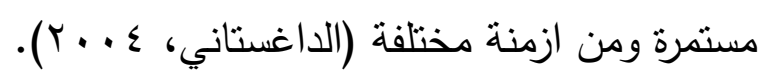


أجريت العديد من الدراسات عن تأثثرات التصحر وزحف الكثبان الرملية لمناطق عديدة من العراق باستخدام تقنيات التحسس النائي ومنها الدراسة الميدانية لتحديد مظاهر التصحر وحركة الكيرات الكثبان الرملية في

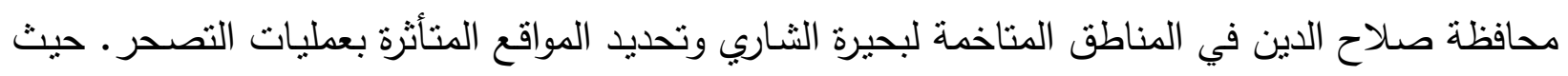

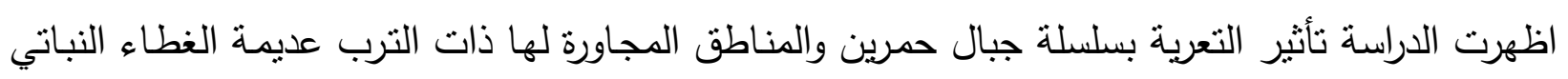

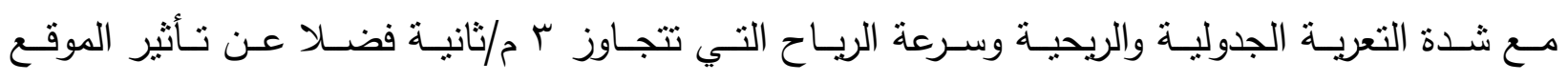

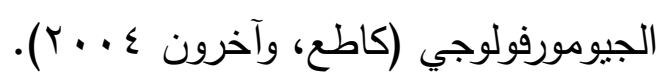
كما أجريت دراسة أخرى لتحديد مظاهر التصحر في محافظة المثنى ،باعتماد العمل الحقلي وتقنية

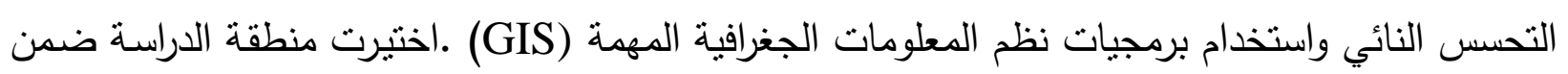

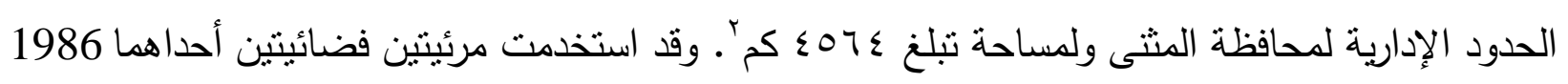

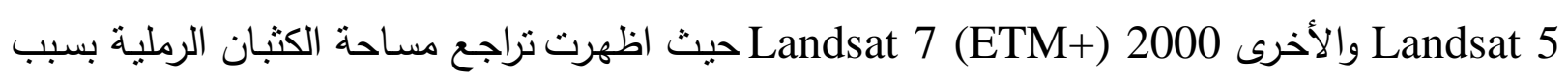
حركة هذه الكثبان جنوبا" مع اتجاه الرياح الثمالية الغربية السائدة.

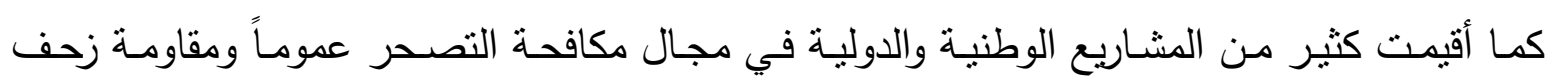

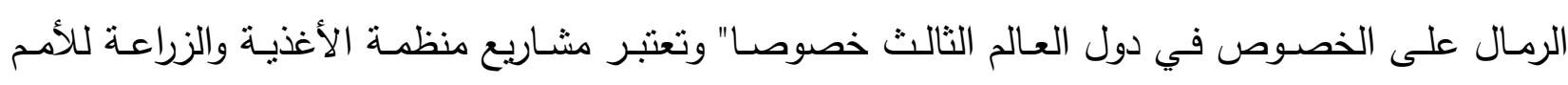

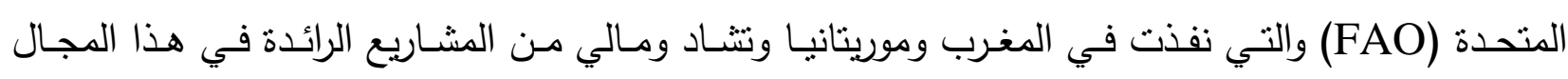

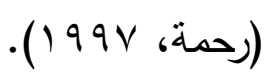

نظرا لما توفره نقنيات التحسس النائي من كفاءة ودقة عالية في قياس وتحديد اتجاه حركة الكثبان

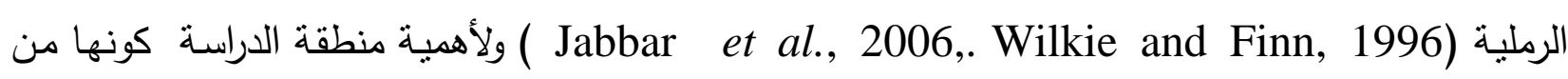

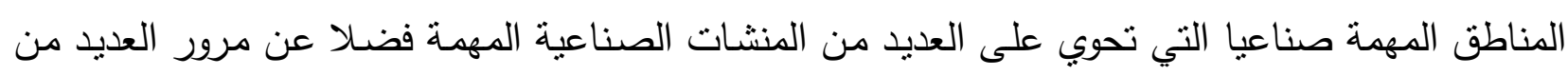

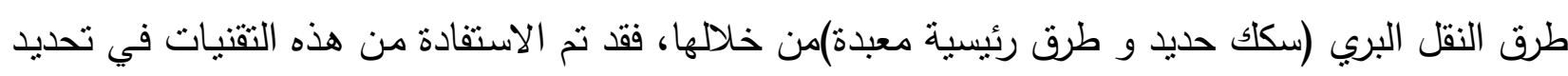

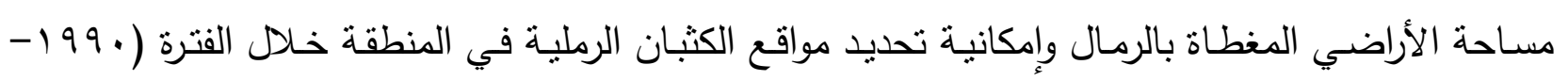

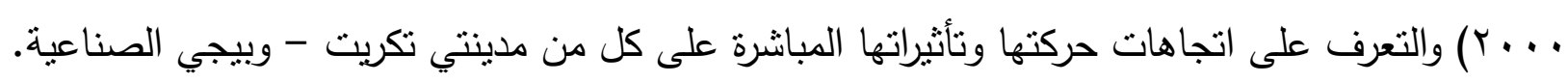

\section{موقع الدراسة}

تقع منطقة الدراسة في المنطقة المحصورة بين منذفض ووادي الثزثار في الجنوب الغربي وباتجاه

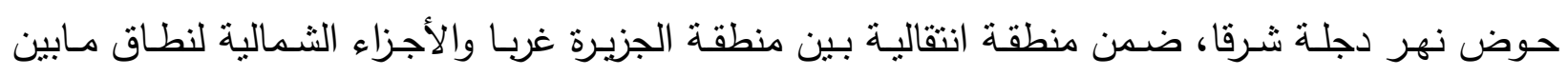

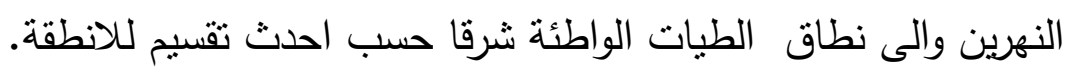

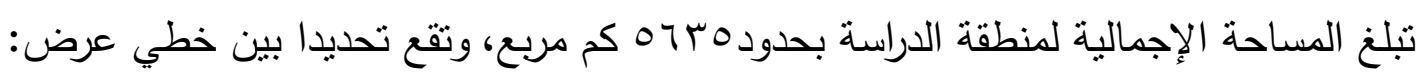

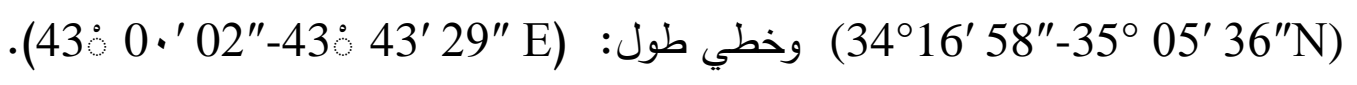




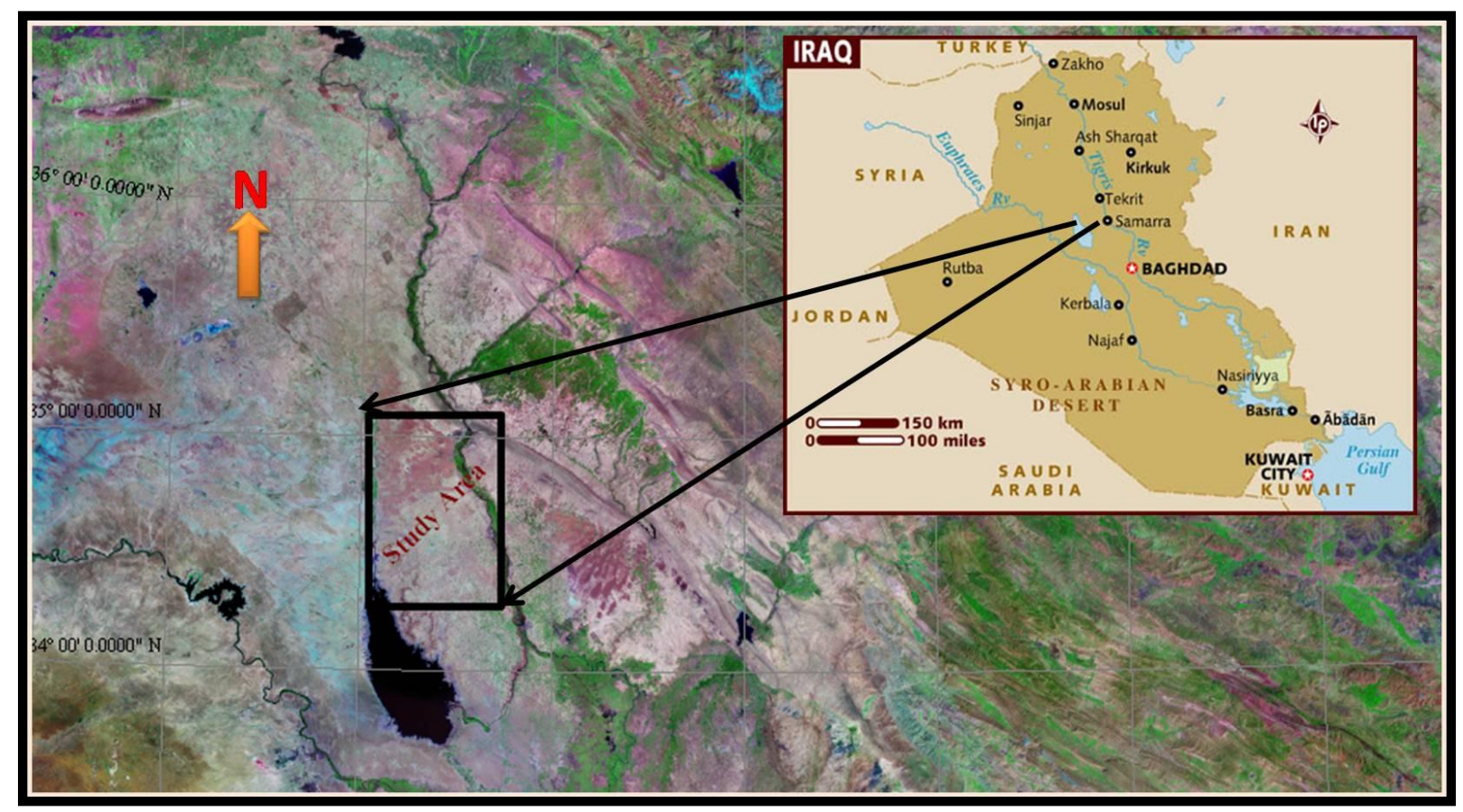

الثكل ا (: موقع منطقة الدراسة.

\section{منهجية البحث والحصول على البيانات}

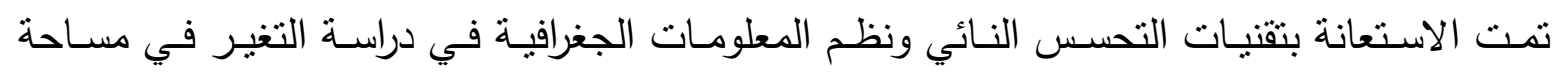

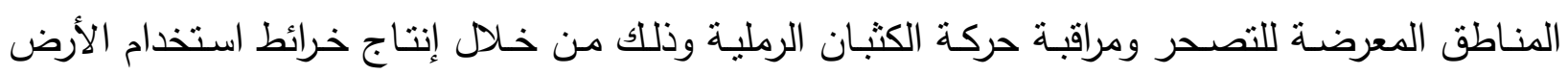

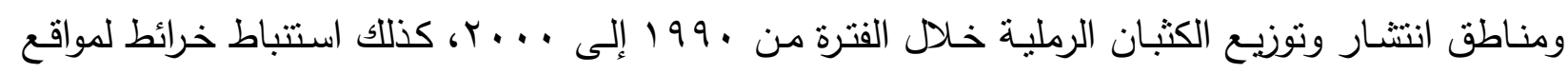

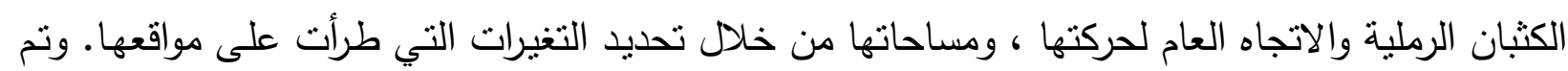

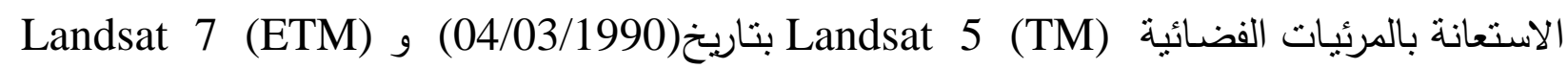

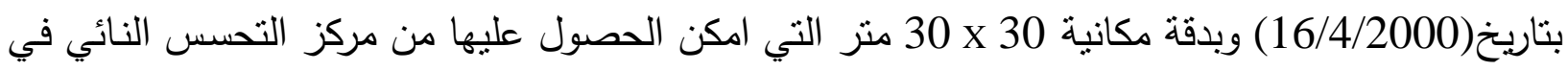

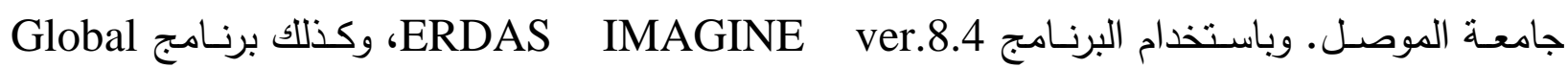
حيث تم إنتاج خرائط لنوزيع المناطق المغطاة بالرمال، وحساب تغيرات استخدام الأراضي 10 لسنطقة البحث.

\section{جيومورفولوجية وجيولوجية منطقة الدراسة}

تقع منطقة الدراسة على الطرف الثمالي لقطاع السهل الرسوبي ، عموما تتميز المنطقة بامتداد جبلي

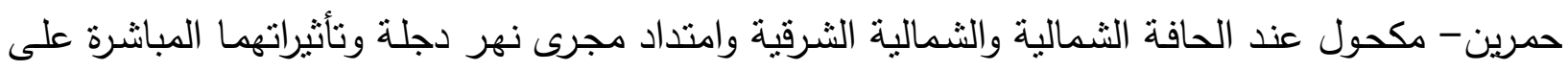
توزيع وانتشار الأشكال الأرضية حيث تنتشر الأشكال ذات الطابع النهري مثل المصاطب الفيضية والمراوح

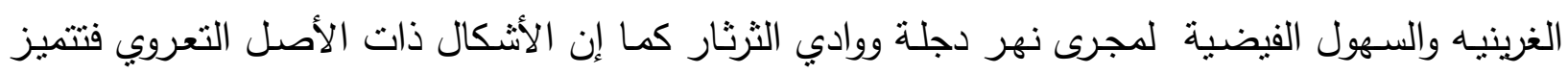


الطرف الثمالي الثرقي والجنوبي الغربي لجبلي حمرين ومكحول، فضلا عن الأثكال ذات الفعل ألريحي والمتمنلة بالكثبان الرملية والنحت الريح(بacoub, 2011).

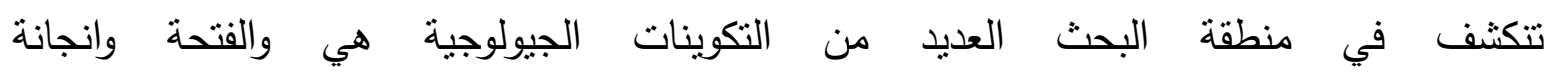

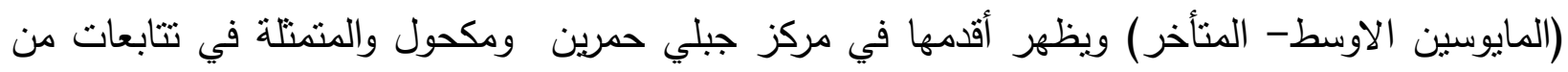
الجبس السميك مع الحجر الطيني والمارلي وحجر الجير كما أن الجبس يعد الأكثر تكثنا في المنطينة

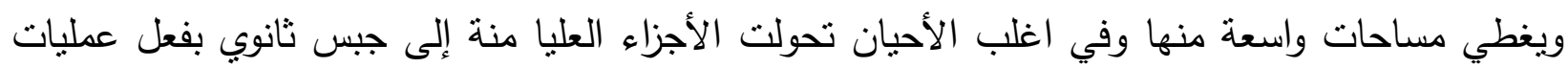
التجوية في حين تتكثف صذور الحجر الرملي والترسبات الفتاتية العائدة لتكوين انجانة عند الحواف الغربية

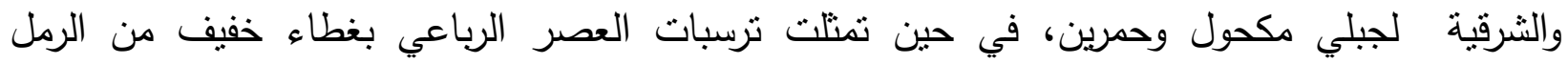

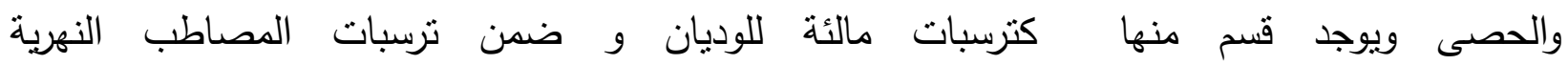
والتي تعود إلى عصر البلايستوسين والمتواجدة بالقرب من نهر دجلة وفي حافات الوديان الرئيسية

.(Yacoub, 2011)

\section{الكثبان الرملية وانتشارها الجغرافي في العراق}

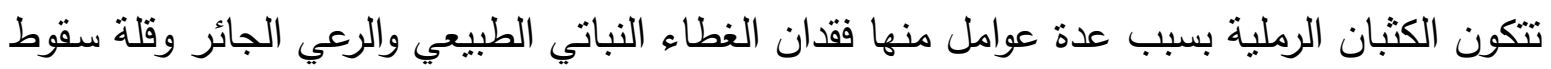

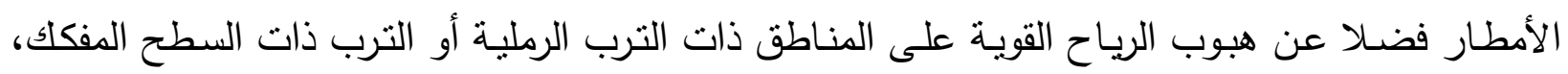

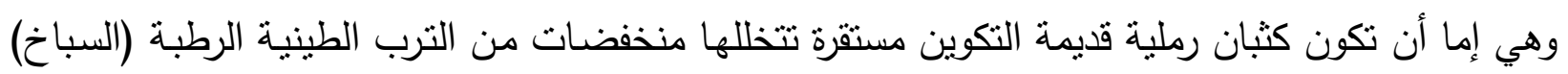

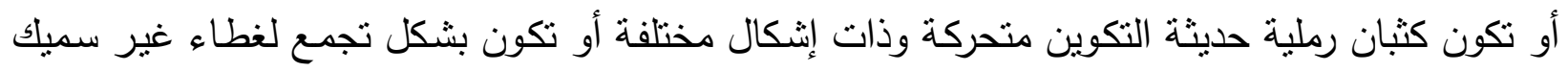
من الأتربة المنقولة بالرياح والتي تتكون بنسبة عالية من دقائق الغرين ولتتكل كثبان رملية (كاذبة) لكونها مشكلة من الأتربة الغرينية الناعمة جدا (حكيم وحميد ، ـ99 (19) ). وتتوزع الكثبان الرملية في العراق بهيئة احزمة على المناطق التالية:

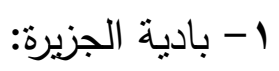

أ- منطقة بيجي ومنطقة العيث في سامراء.

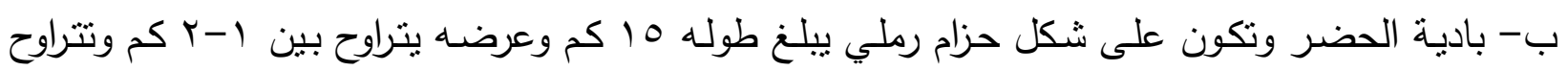

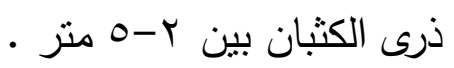

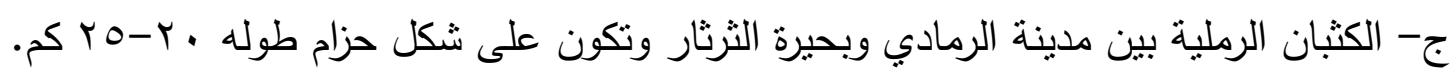
r- (البادية الثمالية:

تتركز في حوض الحماد قرب مدينة طريبيل حيث نتواجد كثبان رملية ثابتة ومتحركة. ب- بادية الجنوبية : يقع هذا الحزام الرملي في الأقسام الثرقية والجنوبية من هذه المنطقة وعلى الجانب الايمن من نهر الفرات

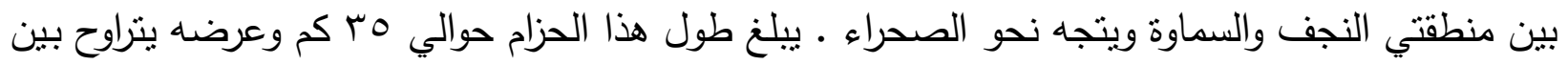

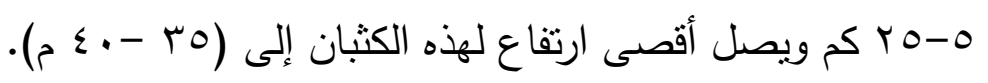


ع - السهل الرسوبي (نطاق مابين النهرين) :

يقع بين نهري دجلة والفرات حيث يبدأ انتشار هذه الكثبان من محافظة بابل الى ان النتصل بان بالاهوار في المنطقة الجنوبية .

ه - بالإضافة إلى ماورد أعلاه فهناك مناطق تتواجد فيها الكثبان الرملية بصورة مجاميع متباينة المساحة

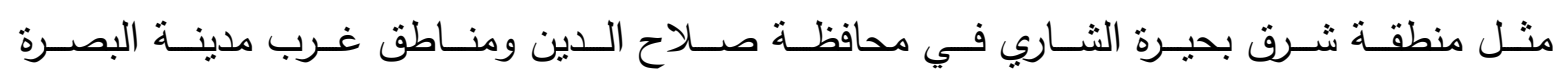
(حكيم وحمبد، . 199 (1) ).

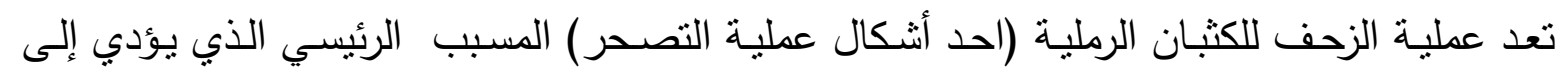

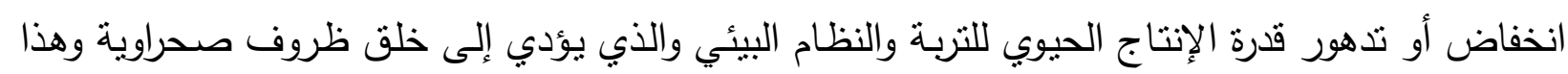

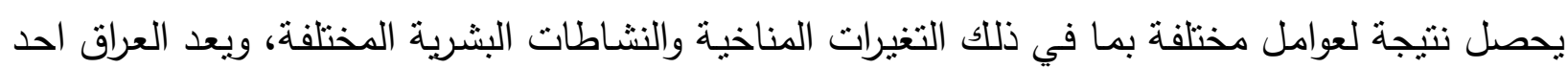

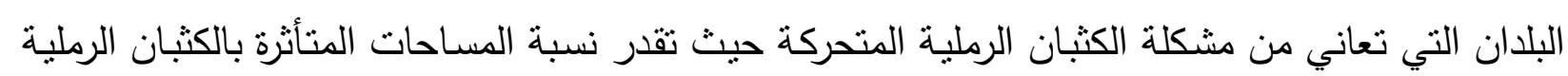

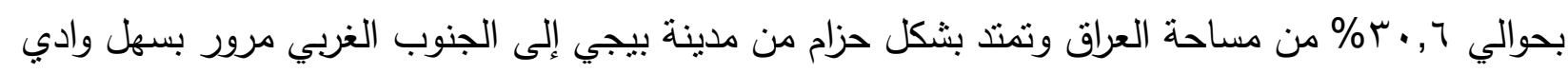

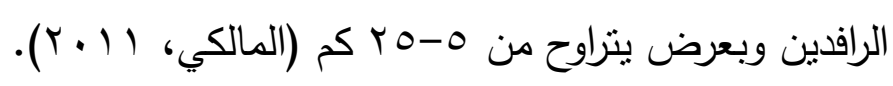

\section{تحليل ومعالجة البيانات}

اعتمدت هذه الدراسة على نمط من المرئيات الفضائية للقمر الأمريكي لاندسات (Landsat) والتي التيات

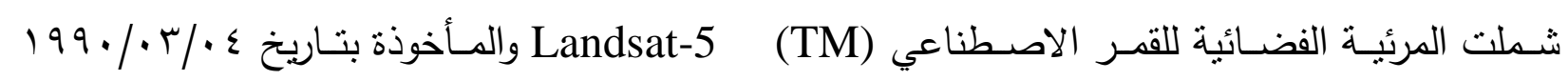

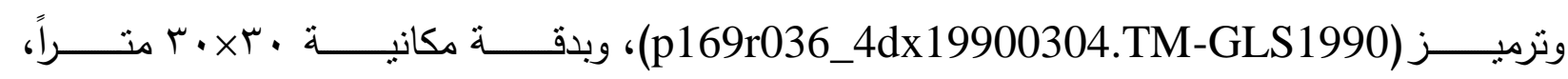

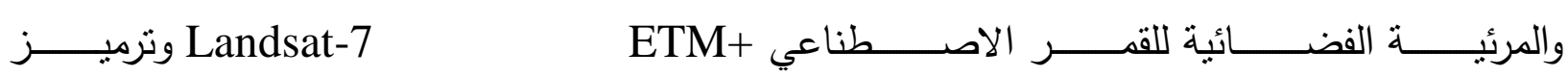

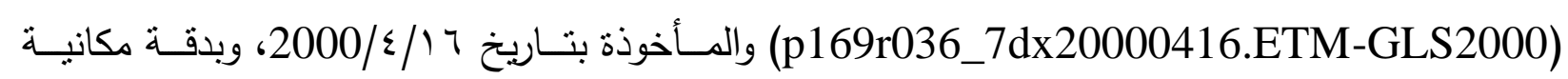
. • التصحيح الهندسي للصورة (Geometric Correction): تم في هذه الدراسة استخدام طريقة التصحيح

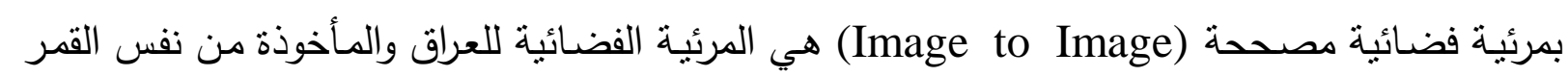

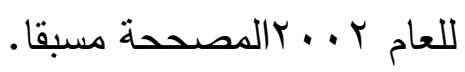
•تحديد منطقة الدراسـة (Subset): تقع منطقة البحث في مسار رقم (Raw I9Path)

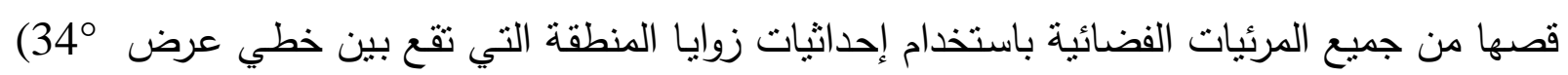

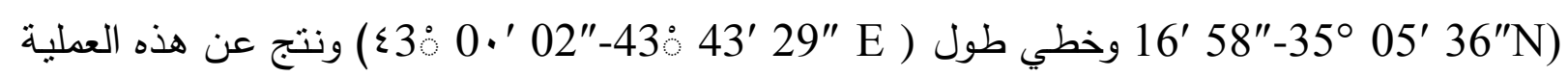

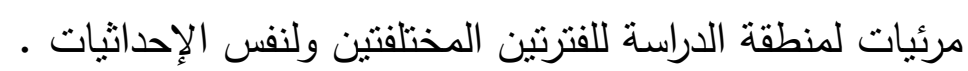
• نم بعد ذللك تحسين المرئية (Image Enhancement) بطريقة (Linear Stretch) وذلك لزيادة الفوارق البصرية والتمييز بين المعالم المختلفة. 
• التصنيف (Classification): تمـ عملية التصنيف بإجراء عملية الفرز لكل عنصر أو صنف في المرئيـة الفضـائية حسب انعكاسـه الطيفي، وتتم عمليـة التصـنيف للمرئيـات عن طريـق اسـتخدام توليفـات مختلفة من الحزم الطيفية (Bands) حتى تبين عدة تركيبات في المحتوى. في هذا البحث استخدمت التوليفة من الحزم الضوئية (V-乏- (Y) ومن أجل إظهار تركيبات المعلومات المراد تحليلها من المرئيات ثم إعطاء كل عنصر بصمة طيفية واحدة في منطقة التصنيف ومختلفة عن بقية العناصر ، ونتج عن هذه العملية مرئيات بهيئة (Classified images)، وموضـح عليها المواقع الجغرافية لمكونات سطح الأرض له (تصنيف استخدامات الأراضي). وقد تم في هذه الدراسة الاعتماد على التصنيف المراقب Supervised) Classification)

\section{النتائج وإلمناقثشة}

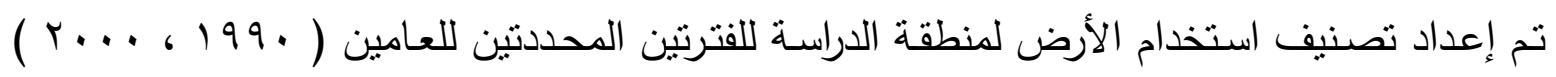

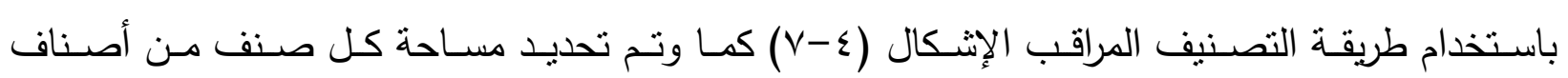
استخدامات الأرض.

أمكن تقسـيم منطقـة الدراسـة إلى تسـعة أصـناف أساسـية ولتمنثل التـرب المختلفـة والغطـاء النبـاتي والمسطحات المائية والصخور وانتشار الكثبان الرملية، وتم تحديد مساحة كل منها وتركز البحث خصوصا على توزيع الكثبان الرملية في المنطقة.

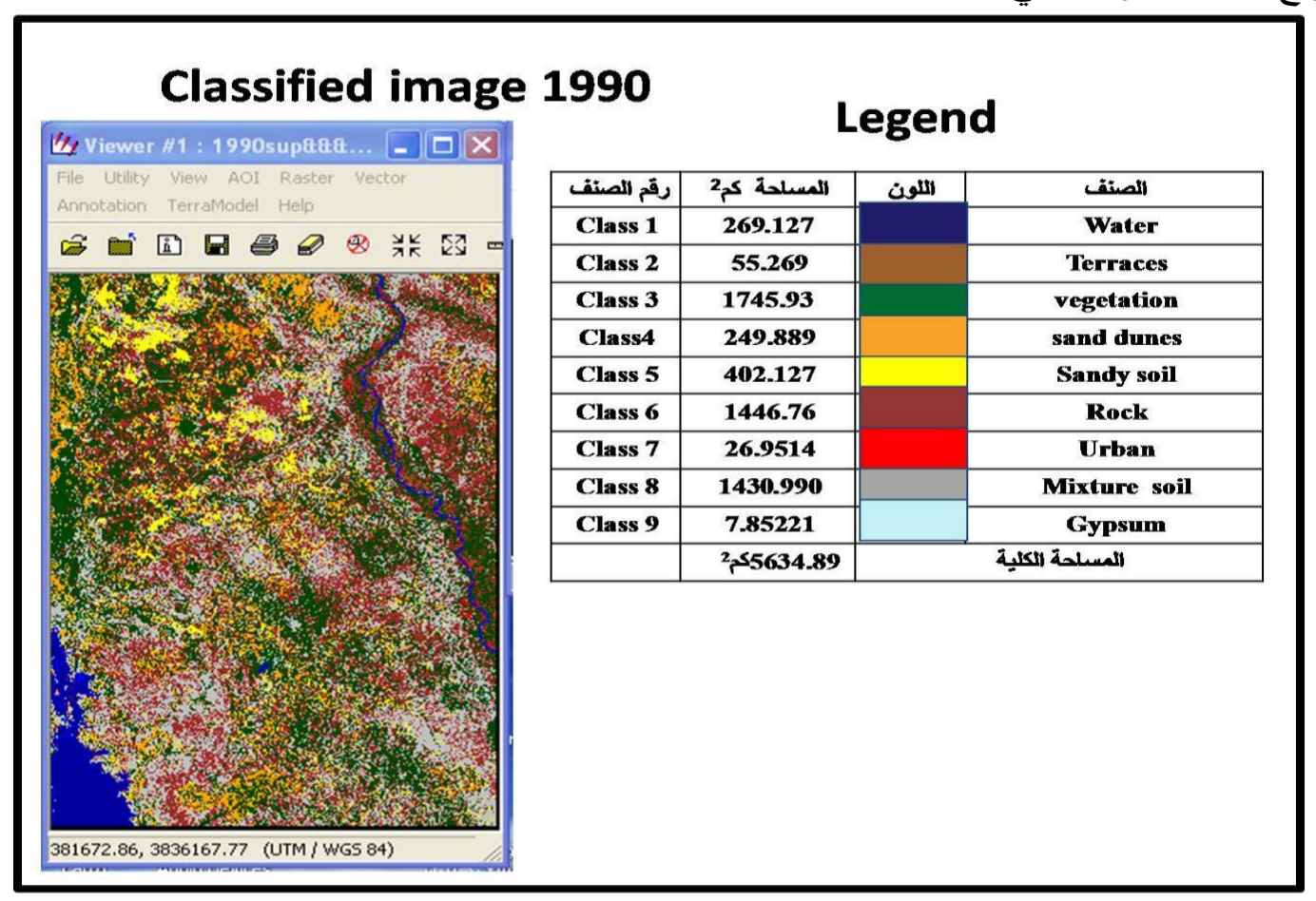

الشكل r: مرئية مصنفة تصنيفا مراقبا لاستخدامات الأرض للمنطقة بتاريخ (ع •/r •/ •99 ) مع مساحة كل منها مقاسه بوحدة (كم مربع). 


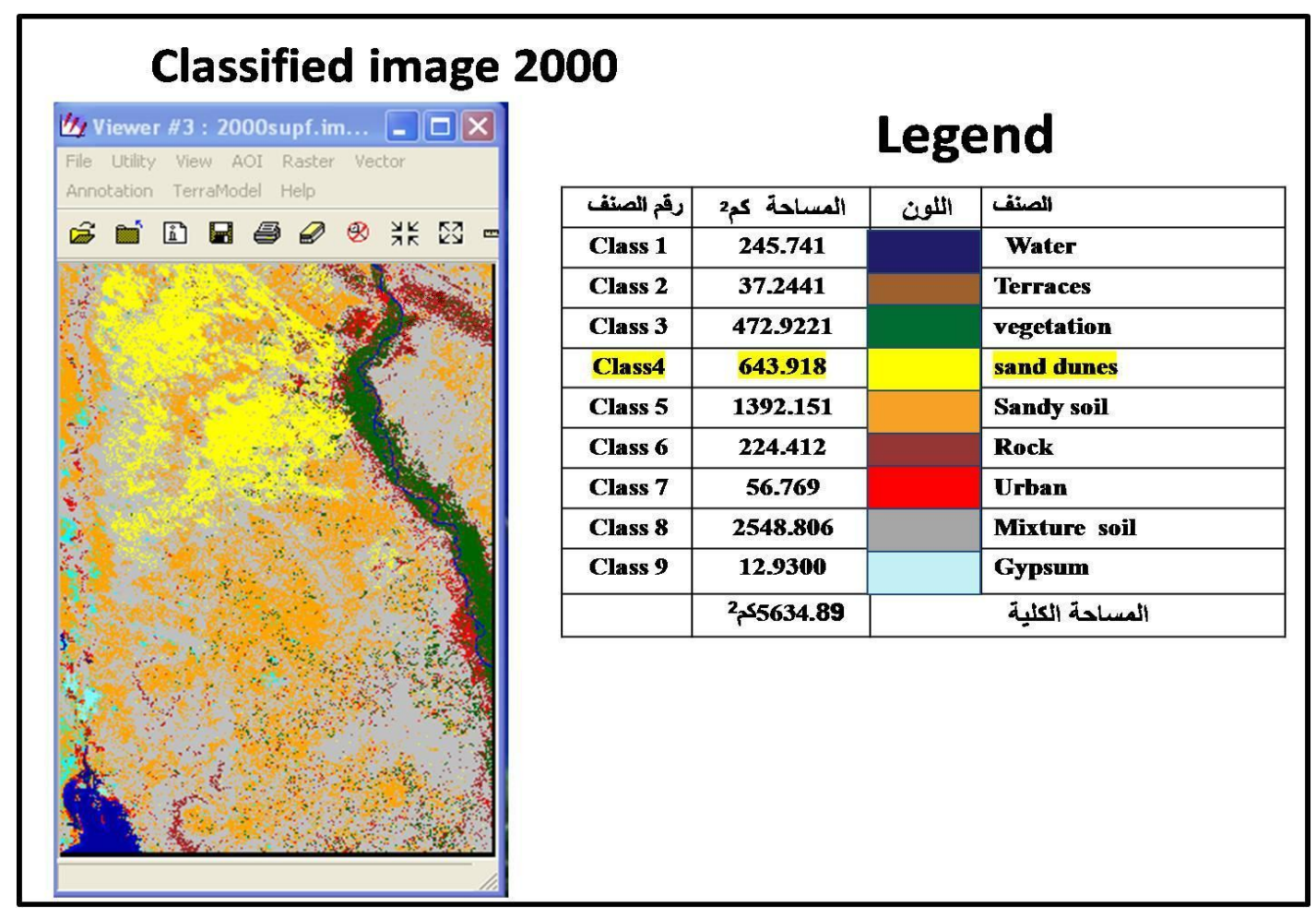

الثكل ب: مرئية مصنفة تصنيفا مراقبا لاستخدامات الأرض لمنطقة الدراسة بتاربخ (7 / / /2000) مع مساحة كل منها مقاسه بوحدة (كم مربع).

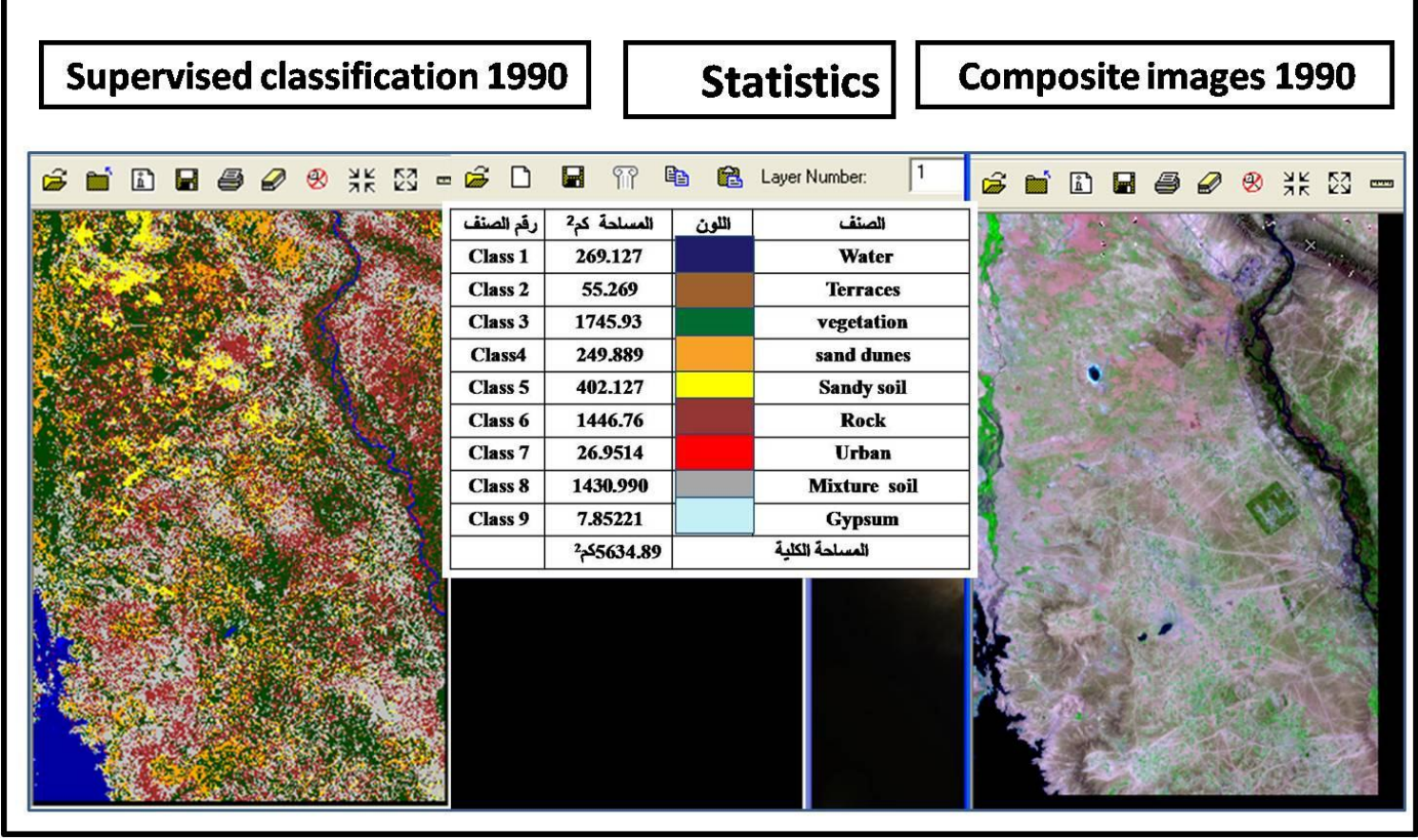

الثكل ؟ : مقارنة بين مرئية فضائية مركبة من دمج القنوات(2,4,7) إلى اليمين ونفس المرئية

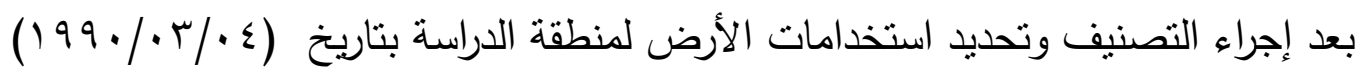
ومساحة كل منها مقاسه بوحدة (كم مربع). 


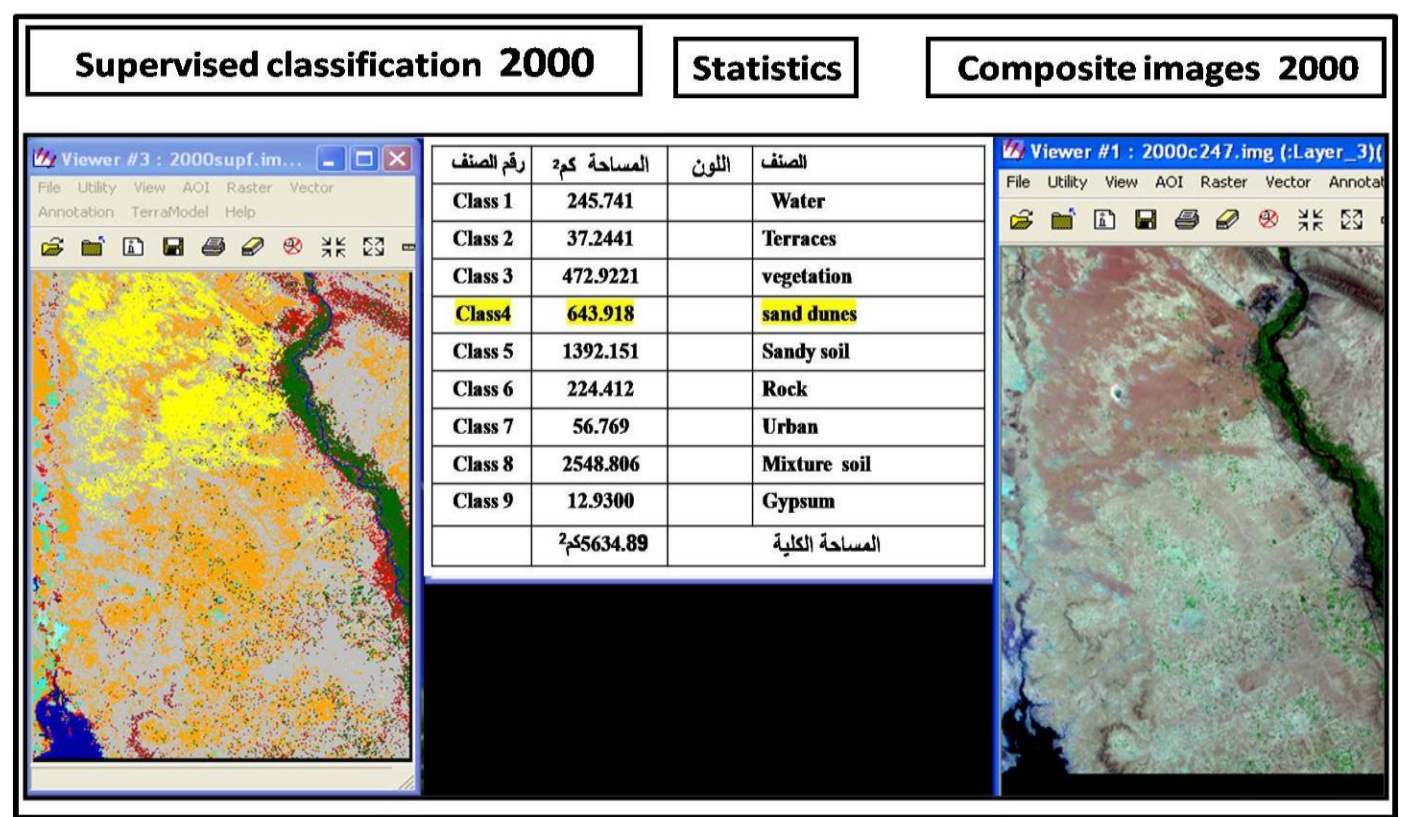

الثكل 0: مقارنة بين مرئية فضائية مركبة من دمج القنوات(2,4,7) إلى اليمين ونفس المرئية بعد إجراء التصنيف وتحديد استخدامات الأرض لمنطقة الدراسة بتاريخ (7 / / /2000) ومساحة

$$
\text { كل منها مقاسه بوحدة (كم مربع). }
$$

حيث بينت النتائج النهائية ما يأتي :

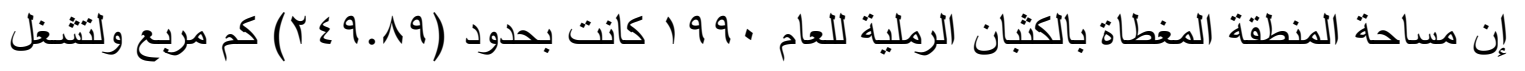

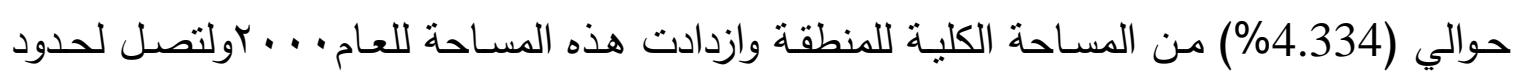
(643.92) كم مربع ولتشغل حوالي (11.439\%) من المساحة الكلية وهذا الرقم يعد رقم كبير حيث

ازدادت مساحة المناطق المغطاة بالكثبان الرملية ثلاثة أضعاف. الثكل (†).

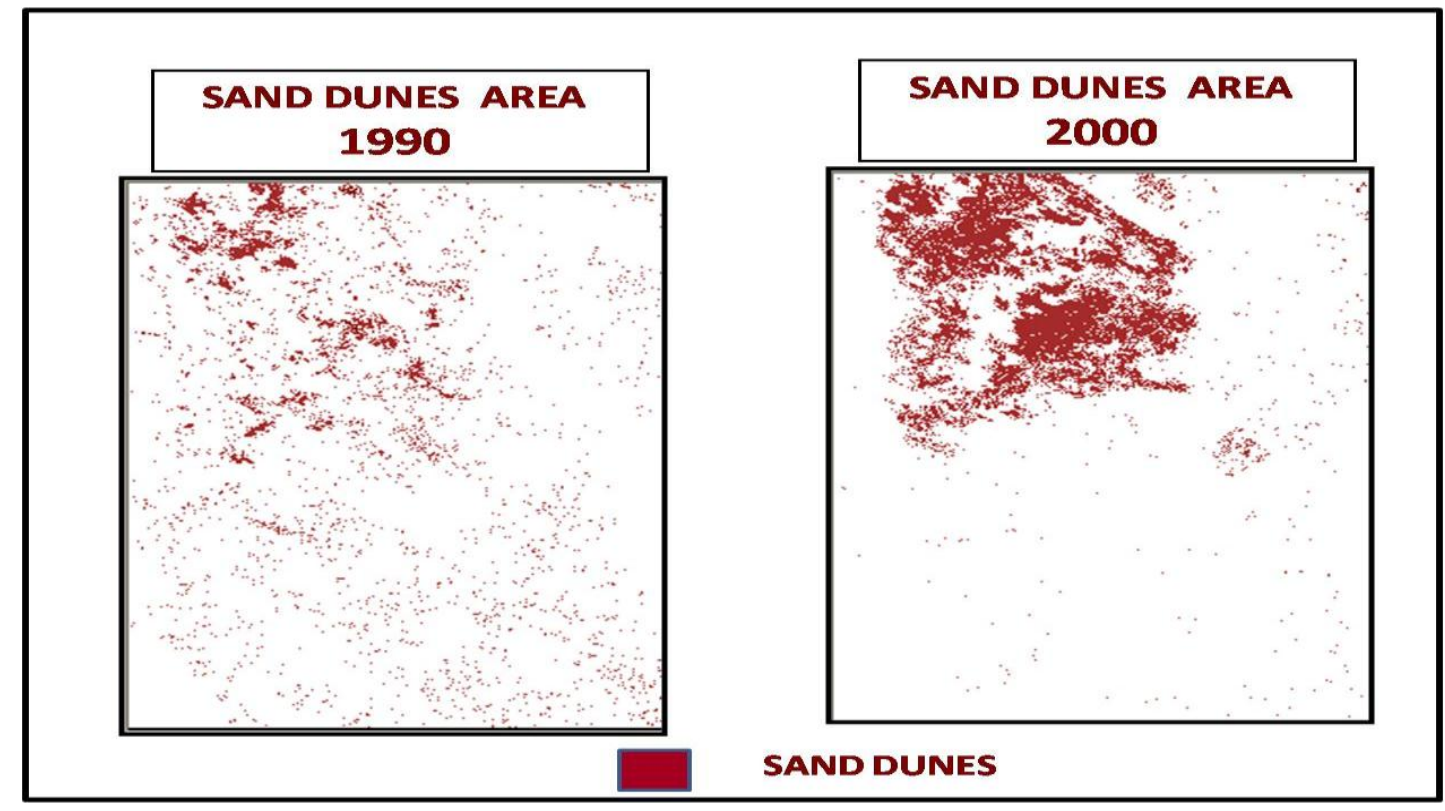

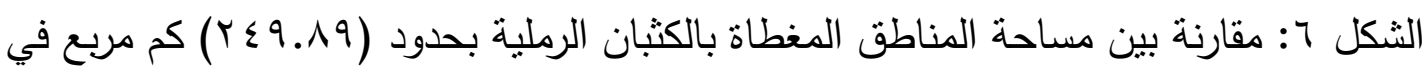

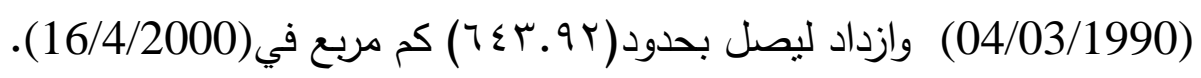


إن اتجاه الزحف الرملي كان على الخصوص باتجاه الثرق وتحديدا باتجاه المنشات الصناعية

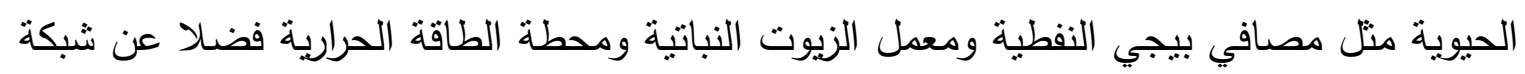
الخطوط البرية (سكك حديد وطريق بغداد-الموصل وطريق بيجي -كركوك) بالإضافة إلى مدينة

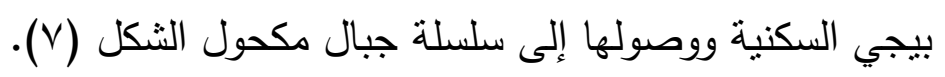

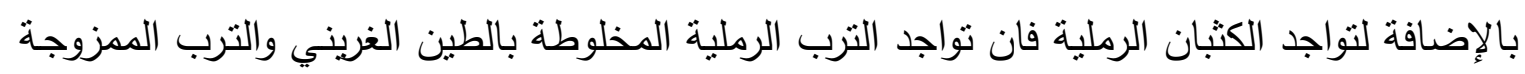

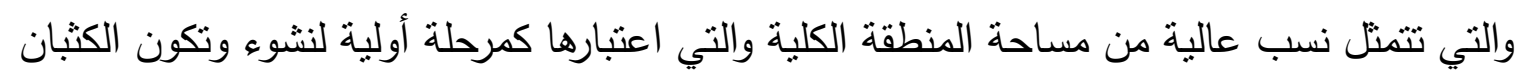

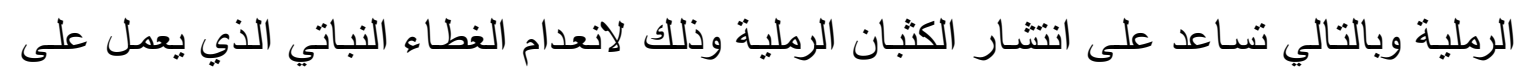
تماسك هذه الترب والرمال.

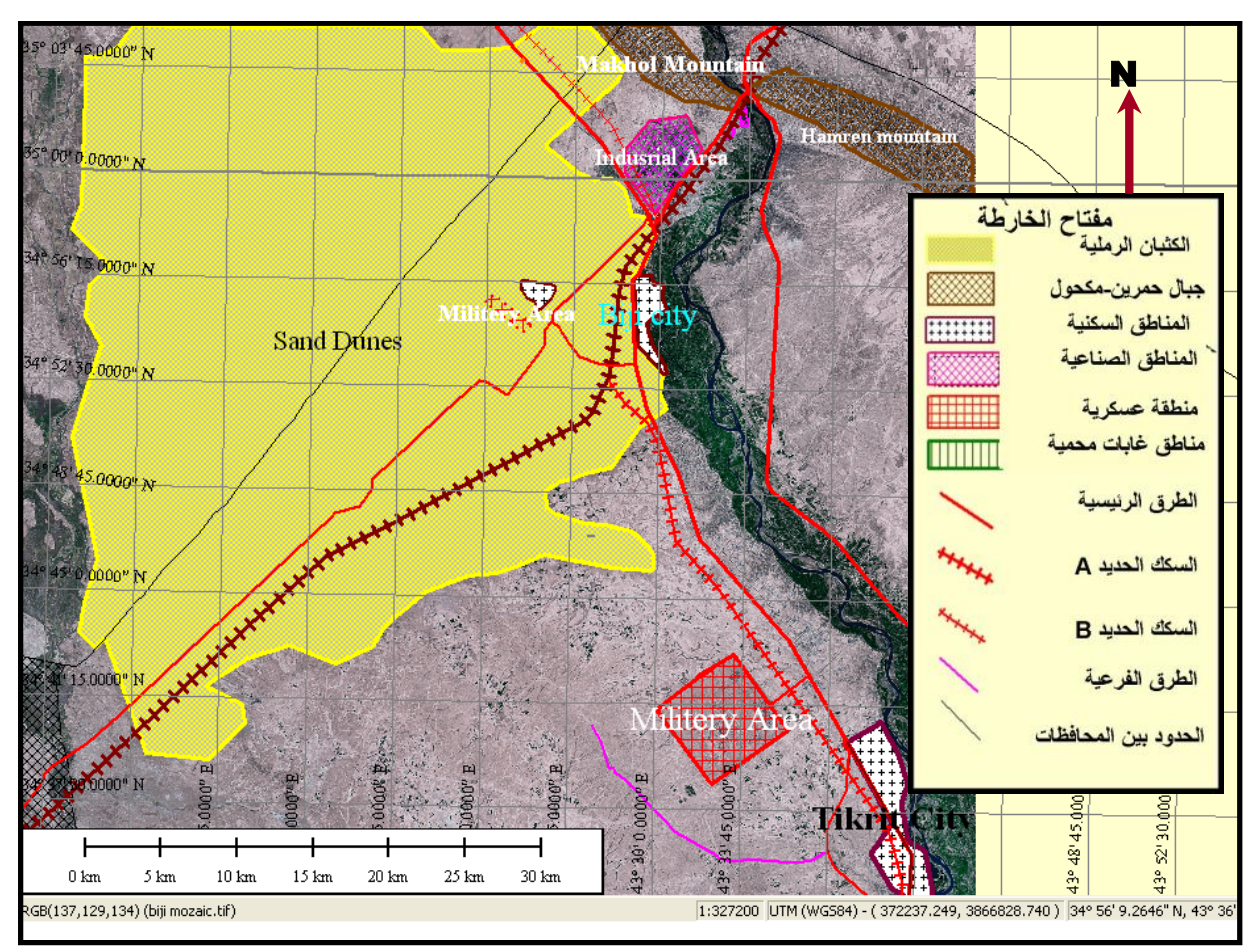

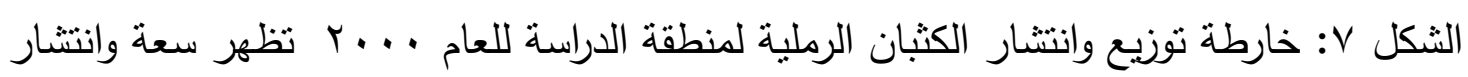

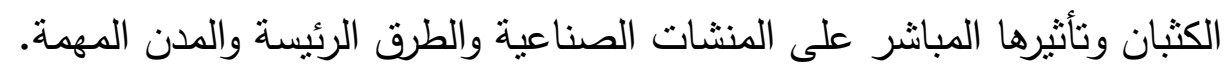

إن نسب المئوية لمناطق الغطاء النباتي الأخضر فيمثل حوالي (30.98\%)للعام • 199 أفي حين تناقصت النسبة للعام ... بحيث بلغت حوالي(8.39\%) من المساحة الكلية والمعلوم بأن الغطاء

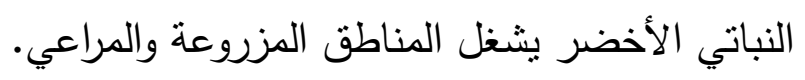

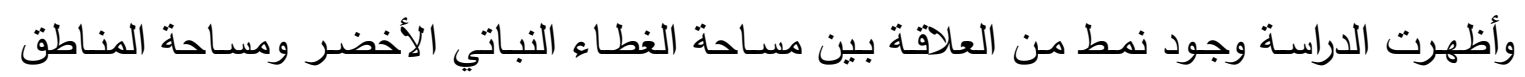

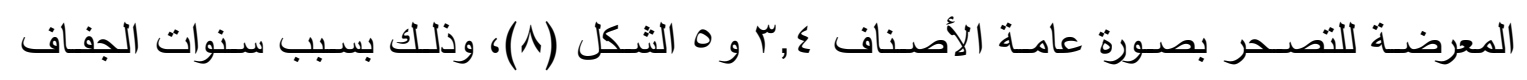

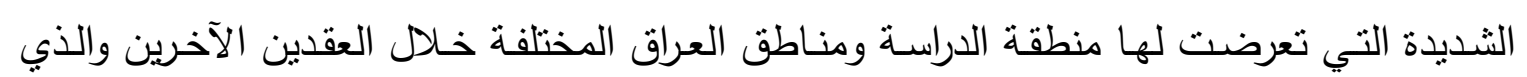


سبب تراجع وتدهور كثافـة الغطاء النباتي رافقته زيـادة مضطردة في مسـاحة المنـاطق المعرضـة المتصحرة.

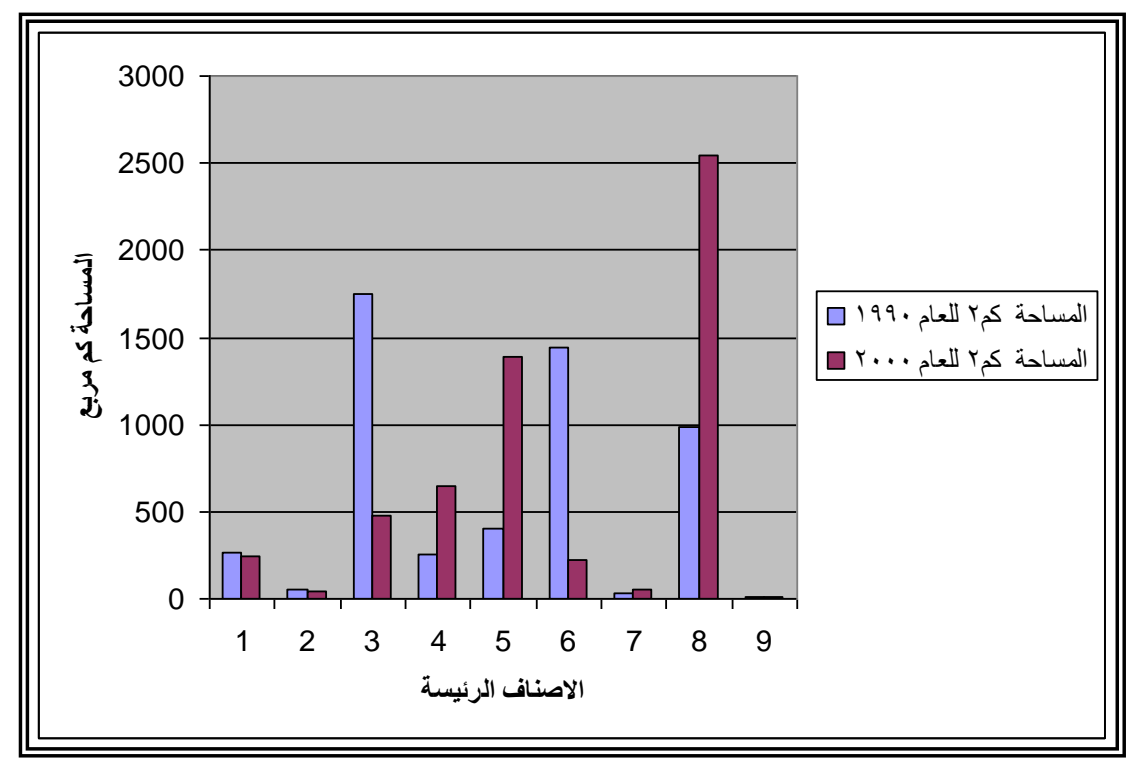

الثكل^ : تمثيل المساحات الكلية للأصناف الرئيسية للمرئيتين المصنفتين بتاريخ .(16/4/2000) و (04/03/1990)

\section{المصادر العربية}

أبا حسين، أسماء علي 999 ا ـ الانسياق الرملي في البحرين - دراسة تطبيقية في محمية العربن. مجلة مركز الوثائق والدراسات الإنسانية (دولة قطر). السنة الحادية عشر، العدد الحادي عشرة،

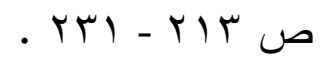

الداغستاني، حكمت صبحي ع . . r. مبادئ التحس النائي وتقسير المرئيات.وزارة التعليم العالي والبحث

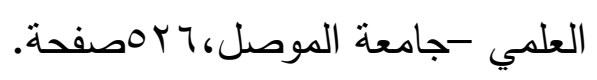

العلي، جميل طارش؛ ذياب، علي حمضي والسعدي، قاسم محمود . . . . تحديد مناطق التصحر باستخدام تقنية الاستشعار عن بعد ونظم المعلومات الجغرافية في محافظة المثى. مجلة أوروك للأبحاث

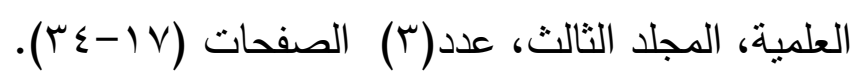
العوضي، جاسم محمد عبد الله ؟... . الانسياق الرملي. سلسلة الكتب المتخصصة، الطبعة الأولى، مؤسسة الكويت للتقدم العلمي، إدارة التقافة العلمية، دولة الكويت، 7 اب صفحة. 
المالكي، عبد الجبار جلوب حسن || ـ ـ ـ الزحف الصحراوي والتهديدات المحتملة للكثبان الرملية في مناطق

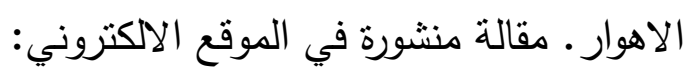

(http://www.estis.net/sites/EnvThiQar/default.asp).

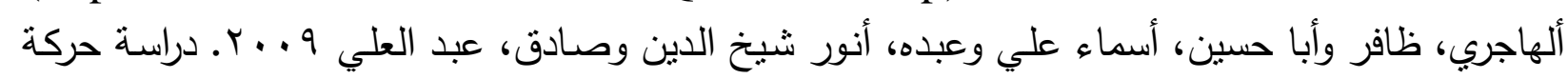

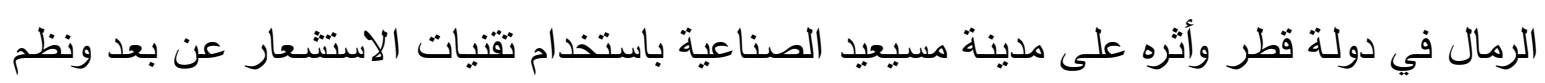

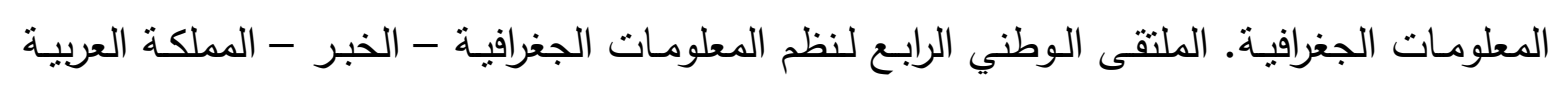

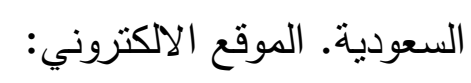

http://swideg.jeeran.com/geography/archive/2010/4/1036435.html

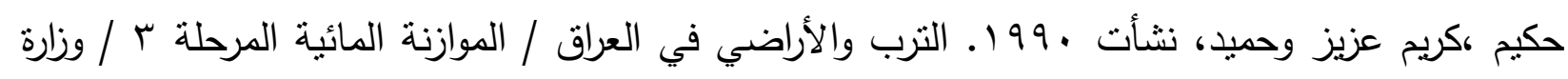

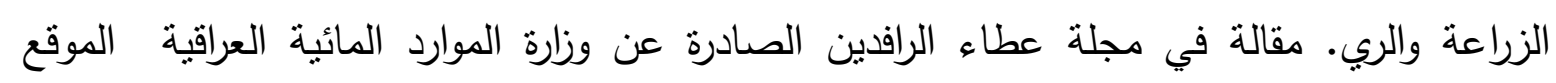

http://www.mowr.gov.iq:81/rafidain-mag/mainview.php?id=127

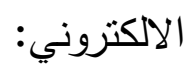

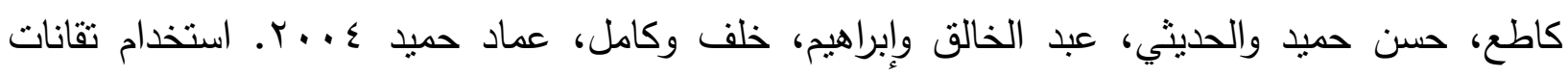

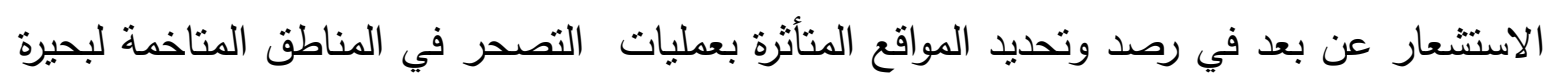

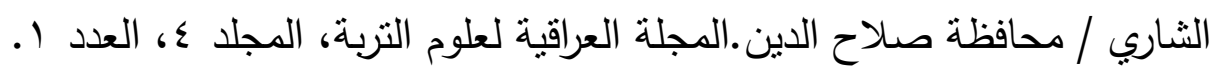

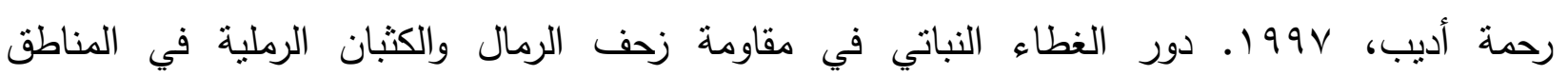

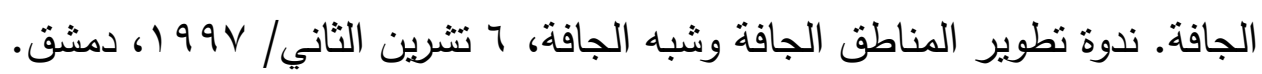

\section{المصادر الأجنبية}

Jabbar, M. T., Chen, X. and Hui L. I., 2006. Rate of Sand Dune Movement and Aeolian Deposition Distribution with the Aid of Geo Information Technology. http://www.aars-acrs.org/acrs/proceeding/ACRS2006/Papers/B-1_B5.pdf Wilkie, D. S., and Finn, J. T., 1996. Remote Sensing Imagery for Natural Resources Monitoring. Columbia. University Press, New York. p. 295. Yacoub, Sabah Y., 2011. Geomorphology of the Mesopotamian .Iraqi Bull. Geol.

Min. Special issue. No. 4, pp. 7 - 32. 